\title{
MODELLING THE RISKS OF EXTREME WEATHER EVENTS TO HOSPITAL INFRASTRUCTURE USING RICH PICTURE DIAGRAMS
}

\section{Abstract}

Climate change has been linked to an increase in the occurrence of extreme weather events. This will expose hospital infrastructure to new risks which are poorly understood. Traditional approaches to risk identification and analysis produce linear, narrow and static risk profiles which fail to consider complex sub-system interdependencies that may assist or hinder healthcare delivery during an extreme weather event. The ability to create resilient hospitals depends on new risk management methodologies which provide an understanding of these complex relationships. To this end focus groups with key stakeholders in three major tertiary hospitals in Australia, are used to construct Rich Picture Diagrams (RPDs) of hospital infrastructure interdependencies under different extreme weather event scenarios. They show that the risks posed to hospitals by extreme weather events cannot be considered in isolation from the surrounding infrastructure, emergency management systems, health systems and communities in which they are imbedded. The new insights provided have major governance and policy implications for those agencies who are responsible for ensuring hospital infrastructure can continue to support the delivery of effective health services during extreme weather events.

Keywords: Extreme weather events, hospitals, risk, resilience, stakeholders, soft systems. 


\section{INTRODUCTION}

It is now widely accepted that over the next fifty years, we are likely to experience more frequent extreme weather events which will test the resilience of national critical infrastructure and services (SSEFR 2011: 5). The inability of healthcare to respond to these new physical and health-related risks is clearly evident in the many recorded instances of hospitals failing to support effective healthcare delivery during such events. For example, in 2005, the Sydney heatwaves highlighted insufficient surge capacity in hospitals to cope with increased demand and changed admission profiles. In 2006, Tropical Cyclone Larry forced the closure of numerous hospitals in Queensland (Queensland Government 2006) and in 2007, floods in New South Wales cut-off hospital power supplies and access to surrounding roads for almost two days (Hunter New England NSW Health 2007). More recently, in 2011, the evacuation of both Cairns Base and Cairns Private Hospitals in the face of Cyclone Yasi is a further graphic example of the inability of hospital facilities to cope with the risks posed by extreme weather events (Miles 2011).

While many aspects of healthcare delivery are being researched in the context of climate change (McCaughrin et al. 2003; Bonnett et al. 2007; Lalonde 2007), research into healthcare infrastructure has been relatively neglected. This is an important deficiency which needs to be addressed as acknowledged by the Australian Science Engineering and Innovation Council (PMSEIC 2007) and by the Council of Australian Governments which recommended that Australian governments should give priority to developing climate change adaptation strategies for Australia's health infrastructure (COAG 2007). To address this challenge, the aim of this paper is to explore the risk exposure of Australiasian hospitals to extreme 
weather events. More specifically, it will do this in the context of the complex system interdependencies which exist in the healthcare sector which have hitherto been ignored.

\section{UNDERSTANDING HOSPITALS AS COMPLEX SYSTEMS}

In understanding the risk exposure of hospitals to extreme weather events, it is important to point to Becker and Carthey's (2007) description of the healthcare systems as a "tangled web of interdependencies". Becker and Carthey make the point that the many problems experienced in healthcare systems around the world are systemic, rather than being caused by any single factor. This means that there is rarely a simple and single solution to any challenge faced. Furthermore, if one is to understand how the health system works in response to an extreme weather event, one must understand the interdependent sub systems that need to interact to enable a hospital to respond effectively. This in turn requires not only an appreciation of specific hospital infrastructures but also an appreciation of the interaction between a hospital system, its users and the wider socio-political and emergency management environment in which it is imbedded. A hospital is a complex organisation with many diverse internal and external stakeholders and functions which combine to deliver appropriate health services to a community. Responses to extreme weather events are similarly complex and involve the interplay of many economic, social, organisational, political and cultural considerations.

Although it is widely acknowledged that health infrastructure systems are complex, we have a poor understanding of the interdependencies between critical health infrastructure subsystems and of the "cascading uncertainties" which they can produce (Arboleda et al 2009, PCI 2011). For example, power outages caused by a 
heatwave can affect heating and cooling systems, waste treatment, sterilisation, and telecommunications, making treatment of patients impossible precisely at the time when admissions are likely to increase. These interdependencies are likely to increase as hospital technologies become more complex through the use of smart grids, virtual power plants, decentralised power production, the integration of fluctuating renewables and the break-up of previously vertically integrated electricity utility companies (Heite et al 2011). Unfortunately, as Koubatis and Schonberger (2005) point out, traditional approaches to risk identification and analysis are unable to help us understand these types of complex and dynamic interdependencies. These approaches and the tools and techniques which underpin them were developed for simple linear systems in relatively stable environments which in turn means that current hospital policies and response strategies to such events are also likely to be linear in nature.

A useful starting point in understanding these interdependencies is Markus et al's (1972:1) systems-based conceptual model which encapsulates the interrelationships between built infrastructure and the wider systems in which it exists (see Figure 1). Despite being over four decades old, the basic construct of the Markus's model holds good today since it views a building facility and its stakeholders as an 'adaptive system' which comprises five key elements (sub-systems): the building system; the environmental system; the activity system; the objectives system and the resources system. These systems are in a dynamic relationship and are not conceived as silos but as discrete but interactive components.

\section{INSERT FIGURE 1 HERE}

Figure 1 Markus's conceptual building sub-systems model (Source: Markus 1971: 1) 
In Markus's model The Building System comprises three interdependent subsystems: Construction (the external envelope; the structure; the division of internal spaces i.e. the building fabric); Services (mechanical and electrical services providing air conditioning; lighting and power) and Contents (furniture and fittings - in a hospital context this would include surgical equipment; beds; diagnostic equipment etc.). The Environmental System refers to the internal building environment created by the Building System which comprises two sub-systems: Spatial (the layout of the facilities; the relationship of one space to another) and; Physical (the air quality; internal air temperatures; infection control etc). The Activity System represents what happens within the facility and comprises several "organisational" subsystems which control the way people interact and work together to enable the Objective System to function, which in a hospital context involves the continuity of health care delivery to the community during an extreme weather event. Finally, the Resources System represents the external "environmental" from which the other sub systems draw to enable them to function effectively. This includes the supply of physical, financial and human resources.

Using Markus' model, Figure 2 shows how an extreme weather event might impact on the environmental; activity; objectives and resource systems of a hospital. In this example, which reflects a number of examples which have occurred in reality, a heatwave causes an electricity supply outage because of excess demand on the national electricity supply system. This in turn causes the hospital to use emergency generators which in turn restricts power supplies internally to essential services such as life-support systems, which in turn causes the cancellation of elective surgery and reduced admissions, which in turn affects the continuity of health care delivery into the community. 
INSERT FIGURE 2 HERE

Figure 2 Possible affects of heatwave on a hospital explored using Markus's Model

While useful in representing hospital sub-system interdependencies, the limitation of Markus' model is its inherent linearity. An alternative technique to illustrate and conceptualise the healthcare system's interdependencies are rich picture diagrams (RPDs). RPDs developed out of soft systems methodology which distinguishes between hard systems and soft systems as described in Table 1.

Table 1: Characteristics of hard and soft systems (Agnew, 1984 p. 168)

\begin{tabular}{ll}
\hline Hard system characteristics & Soft system characteristics \\
\hline Well defined goals & Objectives frequently poorly defined \\
Clearly established boundaries & Decision taking procedures vague \\
Quantifiable performances & Difficult to quantify \\
Clearly structured & Poorly structured \\
Physical systems & Human activity systems \\
\hline
\end{tabular}

Given the attributes of soft systems described in Table 1, soft systems methodologies are likely to be a useful way to understand the complex interdependencies within the healthcare system during an extreme weather event. The RPD technique is one such technique and has been defined as a pictorial summary of the actual situation in the systems world based on enquiries or observations of the "real world" (Patching 1990). In essence, a RPD is a pictorial multi-layered representation of the real world using symbols to represent subsystems and their relationships (of different types - communications, dependencies etc) within a defined system boundary. A typical rich picture diagram from a hospital (our first Case Study) is depicted in Figure 3. This diagram represent pictorially the 
various components of the system affected by a flooding event which are dependent on each other to respond effectively. The effectiveness of the whole system in responding is therefore also determined by how well these interdependencies are recognised and enabled through the various interacting management systems and through the informal actions of human actors who might be forced to move outside those systems (the invisible informal organisation). Physically the system depicted in Figure 3 encompasses a large area with some components of the systems being widely dispersed. For example, one component of the system (hospital stores) is at a physical distance of over 400 kilometres from the base hospital. In a rich picture diagram the nodes are simply pictorial representations of "critical assets" which have been identified as risks with connecting lines which represents dependencies (flows of "resources") between them. For example, in Figure 3, the availability of key maintenance staff (a key risk) depends on the roads being open (another key risk) to get to hospital. The arrow represents the direction of an interdependency and a flow of resources between these two critical asset risks.

In our RPDs there are three types of critical assets:

1. Organisations - suppliers, external service providers, external authorities etc.

2. People - staff, patients, public etc.

3. Physical - buildings, plant, machinery, infrastructure etc.

And there are five types of resource dependencies between the critical assets:

1. Information $-X$ needs information from $Y$ to respond effectively.

2. Financial - $X$ needs money from $Y$ to respond effectively.

3. Power - $X$ needs permission from $Y$ to respond effectively.

4. Material - $X$ needs materials, water, energy etc from $Y$ to respond effectively. 
5. Human - X needs staff, people, emotional support etc from $Y$ to respond effectively.

\section{METHOD}

A multiple case study approach was adopted for our research. Case studies represent the best way to study sub-system interdependencies within a complex open system such as healthcare (Yin 2009). Dooley noted that '... only after the researcher has observed similar phenomena in multiple settings will confirmation or disconfirmation of the new theory begin to take shape and gain substance' (Dooley 2002: 336). Our case studies (see Table 2) were chosen in close consultation with partner health services in Australia and New Zealand. Selected based on their size and age, population dependency, historical climatic records and future climatic predictions, the three case studies comprised Coffs Harbour Base Hospital; Whangarei Hospital; and Ceduna District Health Services. Each of these facilities had previously been subjected flash floods, floods caused by storm surges and heatwaves respectively.

Table 2: Case studies

\section{Case study Description}

1. Coffs Coffs Harbour Base Hospital is the largest hospital on the North Harbour Base Coast of NSW and is the Area's major referral hospital. Many other Hospital health facilities rely on this hospital in the case of a major disaster. The hospital serves a population of about 100,000. Coffs Harbour is classified as a sub-tropical area with warm to hot summers and mild winters and, due to its geographical location, flooding and storms 
Case study Description

are relatively common. In May 2009 floods resulted in the

evacuation of 148 residents from local aged care facilities and in

November 2009, Coffs Harbour was again declared a natural

disaster zone following flooding which caused damage to local infrastructure.

2. Ceduna Ceduna District Health Services provides the primary healthcare to

District Health the residents of Ceduna and surrounds in South Australia around

Services the far west coast of Adelaide. Ceduna has a population of 3,500

people and $24 \%$ of the population are Aboriginal and Torres Strait

Islanders. Ceduna is an arid zone with hot dry summers and very

high temperatures. Although extreme heat is common in Ceduna,

periods of prolonged temperatures in the mid 40 degrees Celsius

range has increased in frequency and intensity in recent years.

3. Whangarei The city of Whangarei is located $160 \mathrm{~km}$ from Auckland, New

Hospital Zealand and is the largest urban centre in the Northland region, serving a population of about 75,000 . The Northland Region has a sub-tropical climate with warm humid summers and mild winters. In summer and autumn, storms of tropical origin may bring high winds and heavy rainfall from the east or northeast. In 2007, Whangarei had its wettest winter since 1973 producing widespread severe flooding and landslips throughout much of Northland. Many buildings were washed away, homes flooded, and many motorists were stranded on flooded roads. Whangarei hospital was forced to use emergency generators, water supplies were affected and 
Case study Description

thousands of residents were left without phones and electricity.

Case study data were collected using a proprietary system called "Risk and Opportunity Management System" (ROMS 2011). Using ROMS (2011) a series of independent focus group sessions were conducted in each case study hospital with key stakeholders who would be involved in the response to an extreme weather event scenario. This scenario was different for each hospital and to ensure it was relevant, was developed in consultation with UNSW's internationally recognised Climate Change Research Centre. The stakeholders involved in the ROMS workshops included facility managers, business managers, emergency staff, nurses, clinicians, hospital administrators, community health specialists etc. They were selected through a standard stakeholder analysis framework developed by Freeman (1984) which classifies stakeholders into three categories according to their importance to the problem being explored. Our focus group participants included only "key" stakeholders who were critical in terms of their ability to influence and be influenced by an extreme weather event. In the ROMS workshops key stakeholders are required through a structured brainstorming exercise to first agree key objectives in responding to an extreme weather event, then to identify and assess the risks and opportunities that may affect the attainment of those objectives, and finally to minimise identified risks and maximise opportunities. ROMS (2011) manages this process in a systematic and consistent way and records the results in a multimedia format. Transcripts of the workshops were then analysed using content analysis to map the interplay of the many interdependent subsystems identified in each case study workshop. 
The strength of the ROMS focus-groups was their ability to provide insights into the participants' knowledge, largely based on past experience. The advantage of using the ROMS structured approach was that it ensured uniformity of discussions in each case study reducing potential bias and facilitating easier cross case study analysis. Within the detailed discussions that occurred in these intensive one-day workshops, many references were made to other actors and resource flows and it is these references which underpinned the construction of the RPDs.

In order to identify system interdependencies from the ROMS focus groups, we analysed co-occurrences of comments from our focus group participants using a pattern recognition technique recommended by Guest and McLennan (Guest and McLennan 2003). By cross referencing these multi-stakeholder accounts, we were able to construct a more accurate picture of what these dependencies and relationships were in practice. Table 2 shows an example of transcript data relating to the risks of not having enough essential supplies on site due to the just-in-time delivery model for logistics in one case study hospital. Thematic nodes from the passage were identified, such as "hospital building", "food", "linen", "stores/supplies", and "contractors", and how one item depends on another was established at this stage. This process requires a level of judgement from the researcher but the risk of subjectivity in analysis was minimised by constant comparison of one link against another. 
Table 3: Coding of interdependencies

Just-in-time models for logistics resulting in reduced on-site stock levels

... Depends on...

1.44.10 PARTICIPANT 1 - [with staffing], you're talking about getting Hospital building Food local people into the hospital, whereas your food comes from Casino, Hospital building your linen comes from Lismore and your stores from Newcastle. So Hospital building Stores/ you are talking about a delay of say, a few hours.

supplies

1.45.20 PARTICIPANT 2 - Again, [we] need to define what the

Food

Contractor

essential supplies are first then we have a better chance of making

Linen

Contractor them available for the period needed.

Stores/ supplies

Contractor

FACILITATOR - Can we put a clause in contractor's contracts so that they must provide during an emergency? PARTICIPANT 2 - [we are] already doing that.

In terms of the mechanics of the production of RPDs, Sutrisna and Barrett note that there are no universal standards or formal techniques (Sutrisna and Barrett 2007). Our use of RPDs was to some extent similar to Sutrisna and Barretts' cross case study comparisons and, like them, we found it useful to standardise the RPD symbols across all three case studies to represent the components of the system in order to achieve a degree of consistency. Sutrisna and Barrett cite the caveat from Checkland and Scholes that RPDs have to be considered idiosyncratic in that they show the preoccupations of their compilers to express relationships and value judgements by finding/using certain symbols to convey the correct "feel" of the situations (Checkland and Scholes 2005). 


\section{RESULTS}

The RPDs for each case study system under stress (a relevant extreme weather event scenario) are illustrated in Figures 3,4 and 5.

INSERT FIGURE 3 HERE

Figure 3 Rich picture diagram of Case Study 1 during and after an extreme weather event

INSERT FIGURE 4 HERE

Figure 4 Rich picture diagram of Case Study 2 during and after an extreme weather event

INSERT FIGURE 5 HERE

Figure 5 Rich picture diagram of Case Study 3 during and after an extreme weather event

The advantage of the RPDs depicted in Figures 3, 4 and 5 is that they can be analyzed visually to reveal information about risk in the system in question. For example, there are three types of assets in terms of their centrality to the system: those with high "in degree" centrality; those with high "out-degree" centrality and; those with high "betweeness" centrality. All of these critical assets are high risks but in different ways. 
In degree centrality

A node with a high in degree centrality has high numbers of incoming arrows and depends heavily on resources from other critical assets. These are therefore highly vulnerable points within the system during an extreme weather event. For example across all three of our case studies, it is apparent that the "patients" and the "staff" nodes depend on a large range of resources. Patients require available and suitable staff to deliver care to the patients, a functional road infrastructure to provide access to and from the hospital, and a functional hospital building from which treatment could be received. Staff require adequate communication channels, safe access to the hospital, and peace of mind that their dependants (eg. children; property) are out of harms' way. Other nodes with a high in-centrality include the visitors (Figure 3) and the public (Figure 4), which in an extreme weather event scenario may depend on the healthcare system to provide communication, medical advice or treatment, and shelter in the form of the hospital building.

Out degree centrality

In contrast, nodes with a high out-degree centrality are critical assets with many outgoing arrows which drive the system and must be maintained to keep the system operating. In reality these nodes may be leaders in the system or communication technologies which are designed to send out instructions. For example, in all three rich picture diagrams the road network is a node with a very high out-centrality. This highlights the importance of being able to gain access to the hospital during a crisis, not only for the patients, but also for external contractors delivering medical and other supplies, for staff and ambulance services, and for transferring patients to 
other referral hospitals. It is interesting to note is that road access is identified as a high risk regardless of the nature of event, which in our case studies range from a short event typically lasting up to 48 hours (flash flooding) to a prolonged event lasting more than two weeks (heat wave).

Betweenness centrality

Those assets with high betweenness centrality sit "between" other assets or groups of assets and control the flow of resources between them. These nodes act as "valves" in systems and represent high risk points in the network because if they break down the system splits into independent silos. There are several examples of betweenness centrality observable in the three RPDs. Or example, in case study 2 (described by Figure 4), the government radio network and the phone services control the flow of information between the state government and the emergency services such as the State Emergency Services (SES), the police and the fire brigade.

Clusters

It is also evident in many RPDs that there are clusters of assets that tend to have higher levels of interdependency than others. For example, in Figure 6 there seem to be three main clusters joined by three main nodes (roads, patients and ambulance). The danger in this type of network is that the system can break into separate parts and become dysfunctional if the connecting nodes are not maintained effectively. These connecting nodes therefore represent high risk points in maintaining the integration of the whole network. 
INSERT FIGURE 6 HERE

Figure 6 Clusters in Case study 1

One of the advantages of viewing the system in this visual manner is the ability to gain an immediate and visceral appreciation of how items seemingly unrelated to the core objective of delivering health care are in fact highly interconnected. For example in an emergency situation the residents of an aged care facility may have to be evacuated to the acute hospital (see Figure 3). The fact that an aged care facility may be privately owned and would not normally come under the control of hospital management is overridden by the need to provide healthcare in time of stress. Other facilities such as emergency command centres and staff property also introduce components which are additional to the norm in terms of governance arrangements. As the name implies emergency command centres only come into play during an extreme weather event or similar crisis situation. Staff property in Case Study 1 refers to the loss of 90 cars which were inundated in a staff car park which had been inadvertently designed as a water retention area.

The three case studies yielded very different RPD's although there were common patterns and linkages to each. For example, all three cases showed a heavy dependence on road access, regardless of the geophysical distinction of each hospital and the type of scenario under discussion. All three cases identified contracted non-core staff (other than essential clinical staff) to be of significance in maintaining functionality of the hospital building, whether it be providing maintenance support for the generator, or delivery of goods and stores to the hospital. All three 
cases also identified the important role of staff dependents and property, especially the safety of the children of staff, on staff attendance at the hospital. By understanding the key drivers that may assist or hinder how each of the objectives are being met, any proposed strategy can be viewed with a clearer understanding as to how it may affect the whole system, not just the item to which it is originally targeted.

\section{CONCLUSION}

The aim of this paper was to explore the risk posed to hospitals by extreme weather events by better understanding the complex system interdependencies within and around them. The Rich Picture Diagrams demonstrate that buildings cannot be treated in isolation from the wider systems in which they exist and that to understand the impact of an external extreme weather event, they must be seen in this system entirety. Our results show that in considering how to respond to extreme weather events it is not enough to focus on the physical aspects of healthcare infrastructure alone. At the same time, it is important to be mindful of the needs of the numerous stakeholders who depend on these facilities and conversely, of the stakeholders on which hospital infrastructure itself depends, to achieve its core objective of supporting the delivery of healthcare to the community in a time of increased need.

It is clear from this research that an understanding of how to create and manage resilient healthcare infrastructure depends, in part, on developing a conceptual understanding of the complex relationships between the various components of a healthcare system which includes emergency services and command centres; offcampus hospital supplies; polyclinics; aged care facilities etc. We have shown how the RPD approach can be a useful tool in providing an insight into these highly 
complex and dynamic system relationships and as such brings a fresh perspective to the design, construction and management of healthcare facilities particularly in terms of the new challenges being imposed on both on buildings and people by extreme weather events.

However, we finish with a warning. Although useful for representing interdependencies, RPDs remain a static representation of the systems our respondents discussed in our focus group sessions. There is no doubt that the system adapts and changes over time in response to these events, sometimes rapidly in response to a sudden crisis and sometimes slowly in response to a creeping crisis. The ability to assess the behaviour of the system over time would provide an even better understanding of the risks posed to healthcare systems by these events.

\section{ACKNOWLEDGEMENTS}

The authors wish to acknowledge the contribution of our partners in this research: Prof Andy Pitman, Co-director of the Climate Change Research Centre at UNSW; Prof Tony McMichael and Dr Keith Dear, National Centre for Epidemiology and Population Health at ANU; Mr Mark Meurisse of Palisade Asia-Pacific Pty Limited; and our industry partners NSW Department of Health, Government of South Australia Department of Health and New Zealand Ministry of Health.

\section{REFERENCES}

Agnew, C. T. (1984). Checkland's soft sytems approach - a methodology for geographers? Area, 16(2), 167-174. 
Arboleda, C. A., Abraham, D. M., Richard, J.-P. P., \& Lubitz, R. (2009). Vulnerability Assessment of Health Care Facilities during Disaster Events (). Journal of infrastructure systems, 15(3), 149-161.

Becker, F., \& Carthey, J. ( 2007). Evidence-Based Healthcare Facility Design: Key Issues in a Collaborative Process Paper presented at the Interdisciplinarity in Built Environment Procurement CIB W092, University of Newcastle.

Bonnett, C J, Peery, B N, Cantrill, S V, Pons, P T, Haukoos, J S, McVaney, K E and Colwell, C B (2007) Surge capacity: a proposed conceptual framework. "The American Journal of Emergency Medicine", 25(3), 297-306.

Checkland, P B and Scholes, J (2005) "Soft Systems Methodology in Action". Chichester: Wiley.

COAG (2007) National Climate Change Adaptation Framework. Council of Australian Governments, Canberra, Australia.

Dooley, L. M. (2002). Case Study Research and Theory Building. Advances in Developing Human Resources, 4(3), 335-354.

Guest, G., \& McLennan, E. (2003). Distinguishing the Trees from the Forest: Applying Cluster Analysis to Thematic Qualitative Data. Field Methods, 15(2), 186201.

Hiete, M , Merz, M and Schultman F (2011) Scenario-based impact analysis of power outages on healthcare facilities in Germany, Disaster Resilience in the Built environment, 2 (3) 222-245

Hunter New England. ( 2007). Storm devastation brings out the best in us. NHE Health Matters 
Koubatis, A., \& Schonberger, J. Y. (2005). Risk management of complex critical systems. Int. J. Critical Infrastructures, 1(2/3), 195-215.

Lalonde, C (2007) Primary healthcare organizations facing a disaster: the Quebec experience. "Disaster Prevention and Management", 16(1), 42-55.

Markus, T A, Whyman, P, Morgan, J, Whitton, D, Maver, T, Canter, D and Fleming, J. (1972) "Building Performance". London: Applied Science Publishers Ltd.

McCaughrin, W. C. and Mattammal, M. (2003), 'Perfect storm: Organizational management of patient care under natural disaster conditions', Journal of Healthcare Management, 48 (5), pp 295-308.

Miles, J. (2011). Cairns hospital open again after Cyclone Yasi. Courier Mail. Retrieved 19 April 2011 from http://www.couriermail.com.au/news/queensland/cairns-hospital-open-again-aftercyclone-yasi/story-e6freoof-1225999549260

Patching, D. (1990). Practical Soft Systems Analysis. London: Pitman Publishing.

$\mathrm{PCl}$ (2011) Barriers to effective climate change adaptation, Productivity commission issues paper oct 2011, Prod commission, commonwealth gov of Australia

PMSEIC Independent Working Group (2007) "Climate Change in Australia: Regional Impacts and Adaptation - Managing the Risk for Australia". Canberra: Report Prepared for the Prime Minister's Science, Engineering and Innovation Council.

Queensland Government. (2006). Tropical Cyclone Larry Report Retrieved 29 August, 2006, from http://www.disaster.qld.gov.au/news/view.asp?id=1274 
ROMS (2011) Risk and opportunity management system, Cell-Media, Perth, Australia, www.risk-opportunity.com

SSEFR (2011) Climate resilient infrastructure: preparing for a changing climate, Secteratry of state for environment, food and rural affairs, H M Government, HMSO, London UK

Sutrisna, M., \& Barrett, P. (2007). Applying rich picture diagrams to model case studies of construction projects. Engineering, Construction and Architectural Management, 14(2), 164-179.

Yin, R. K. (2009). Case Study Research: Design and Methods, 4th ed. London: Sage Publications. 


\section{FIGURES}

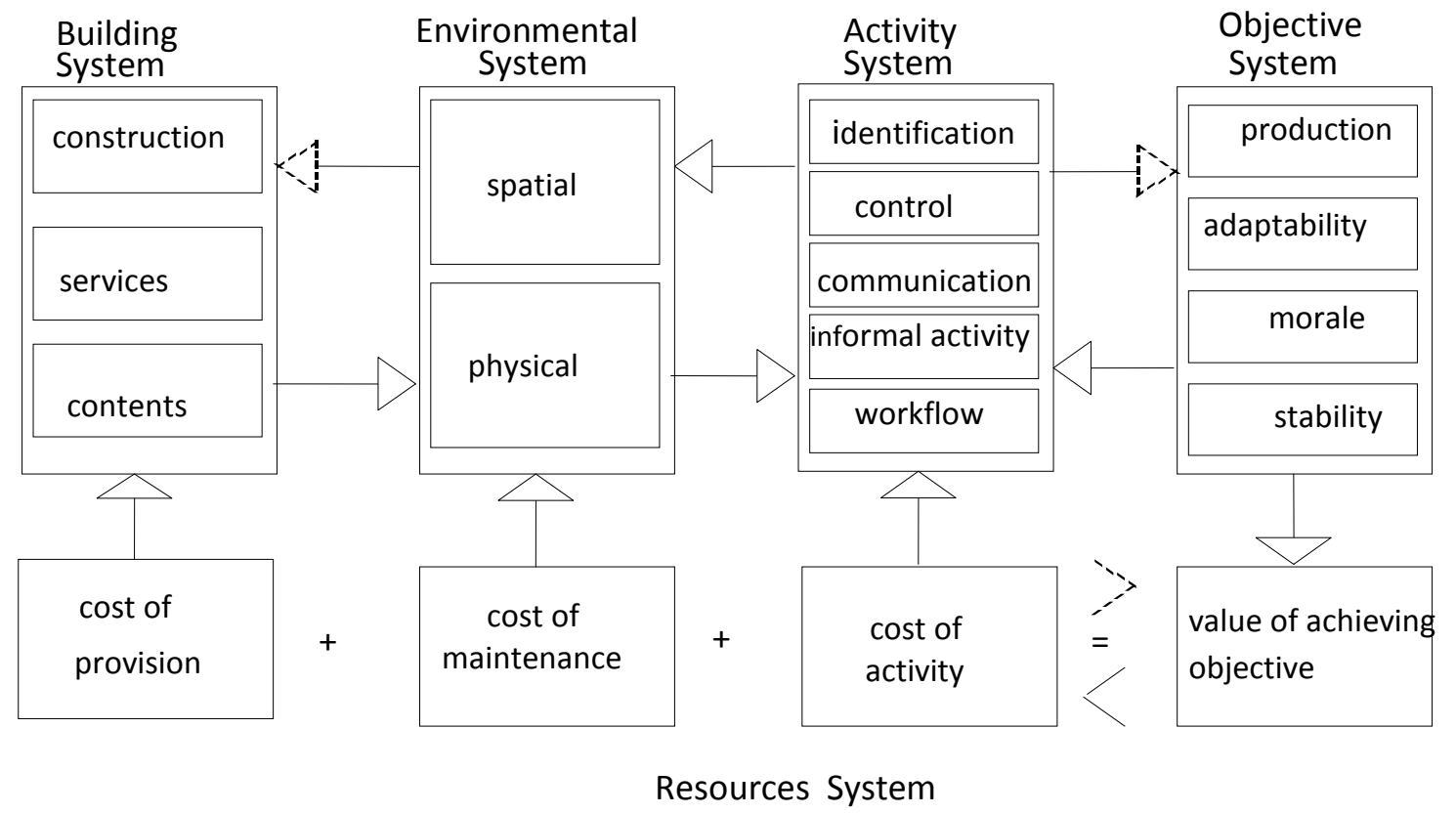

Figure 1 Markus's conceptual building sub-systems model (Source: Markus 1971: 1) 


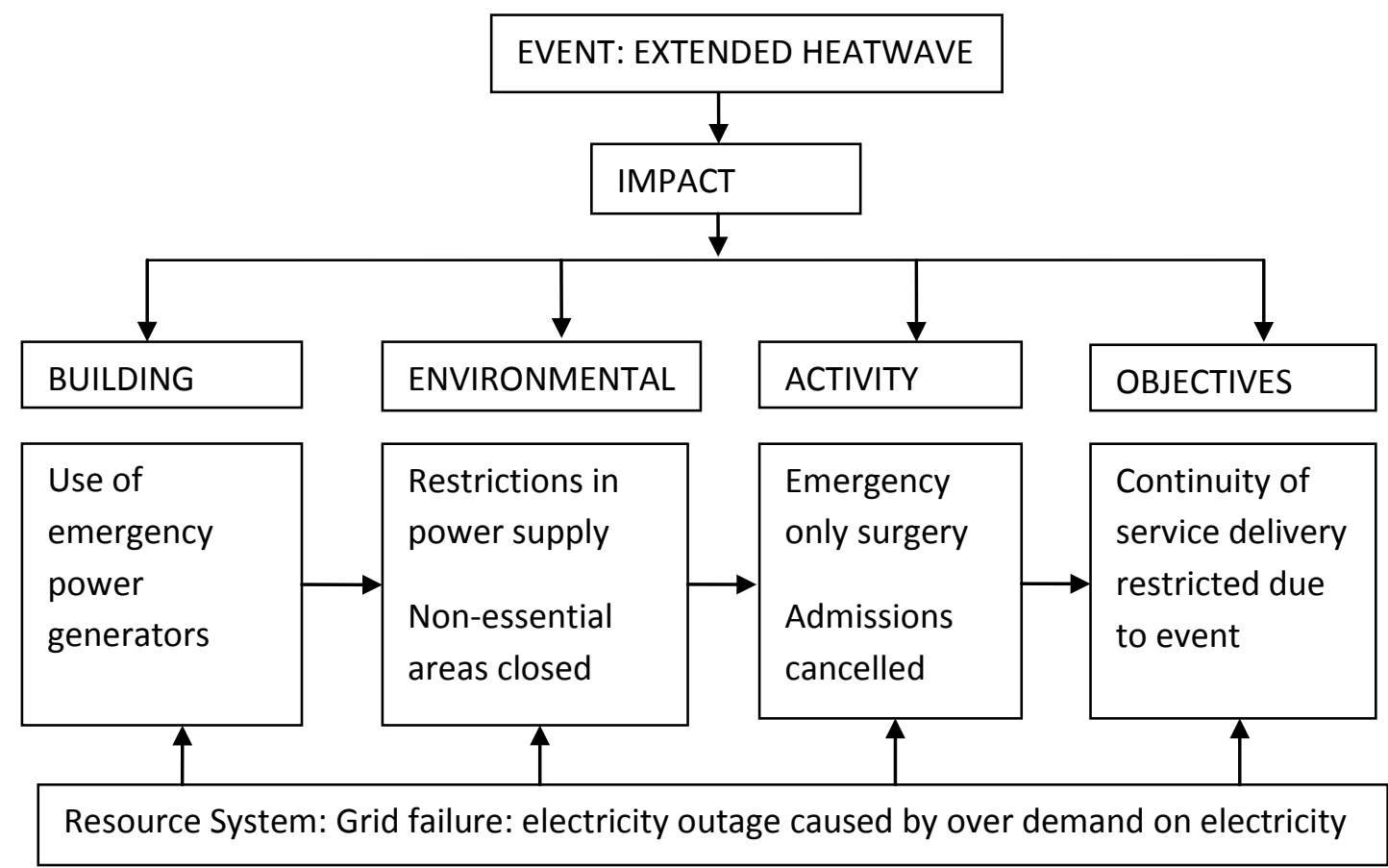

Figure 2 Possible affects of heatwave on a hospital explored using Markus's Model 


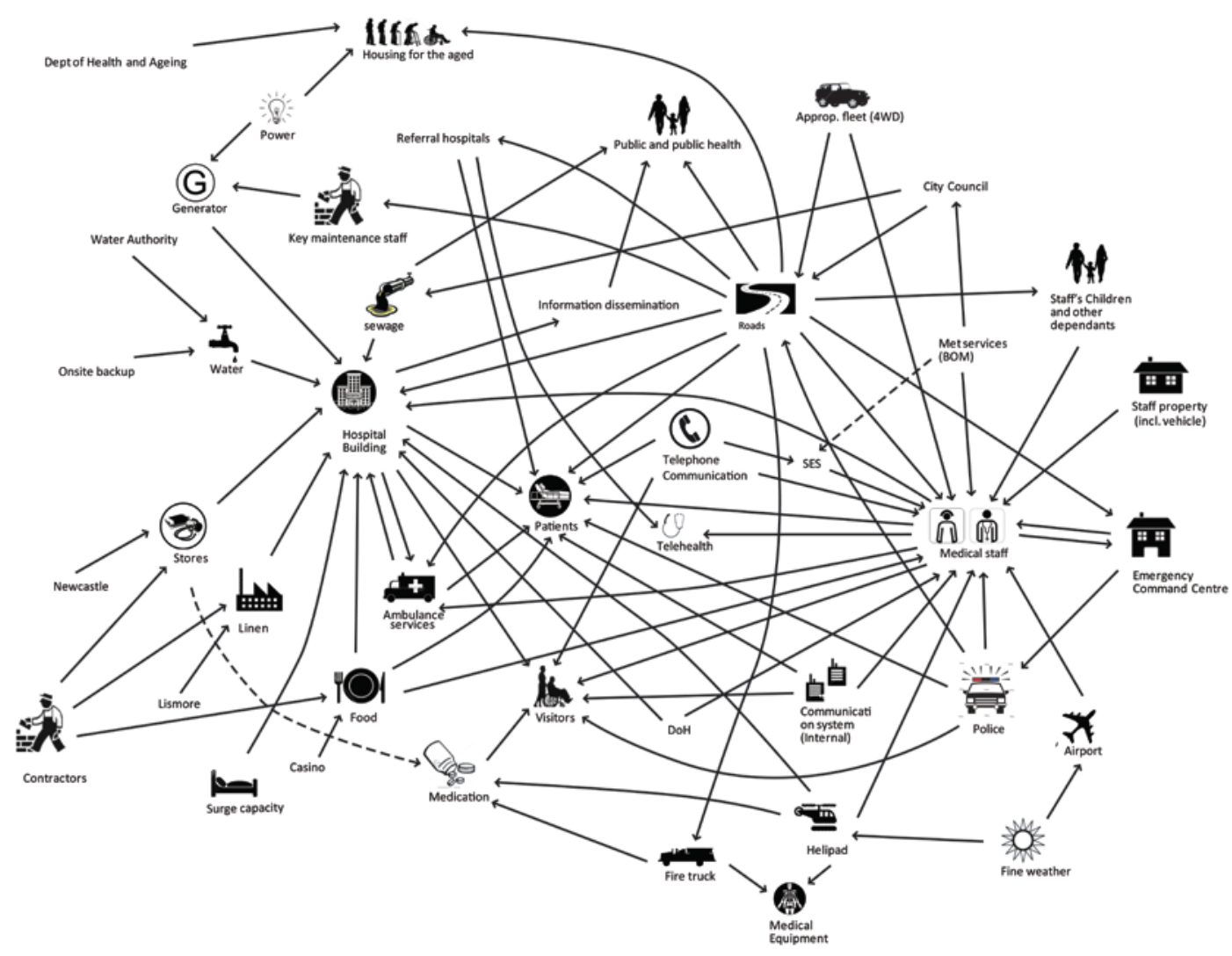

Figure 3 Rich picture diagram of Case Study 1 during and after an extreme weather event 


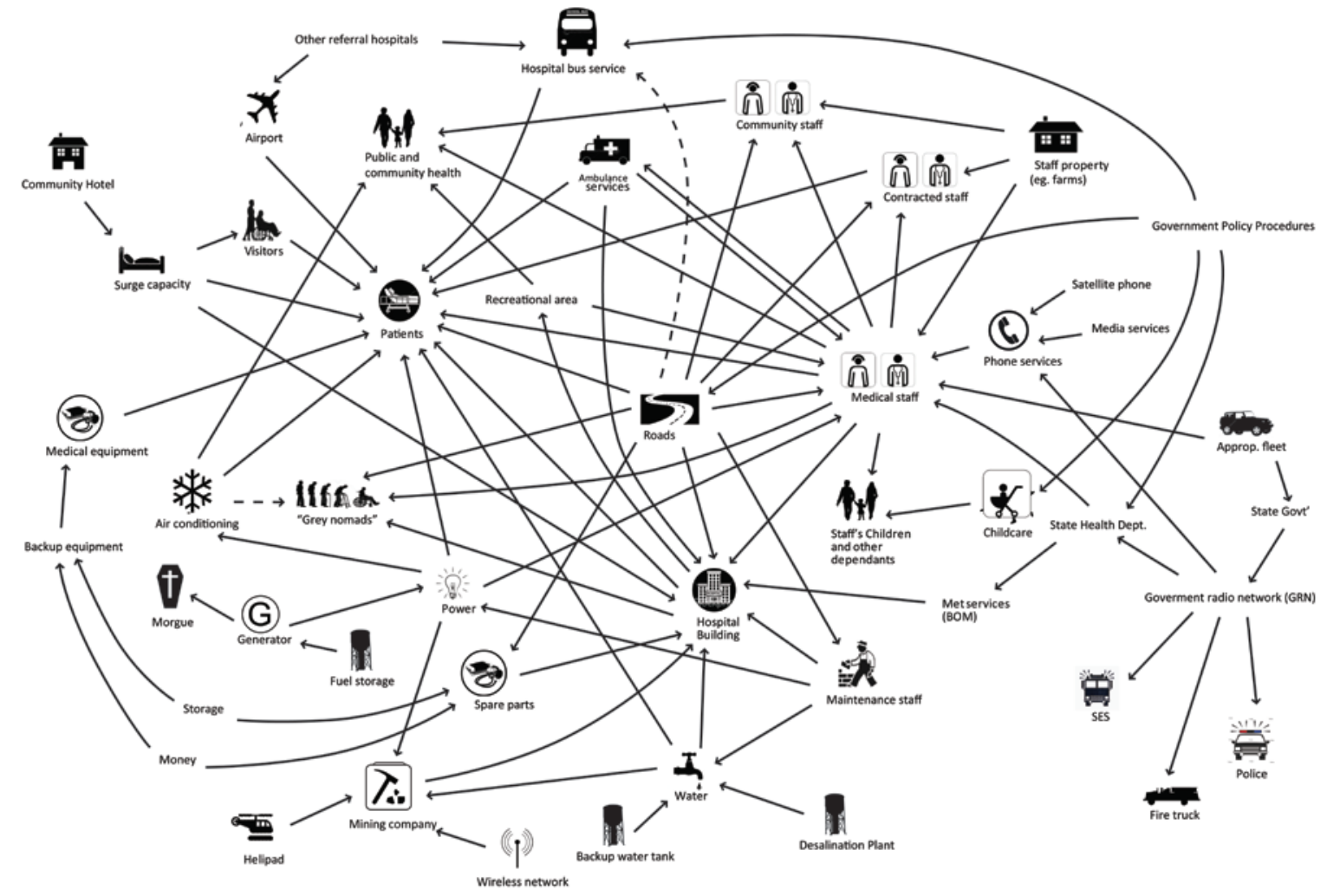

Figure 4 Rich picture diagram of Case Study 2 during and after an extreme weather event 


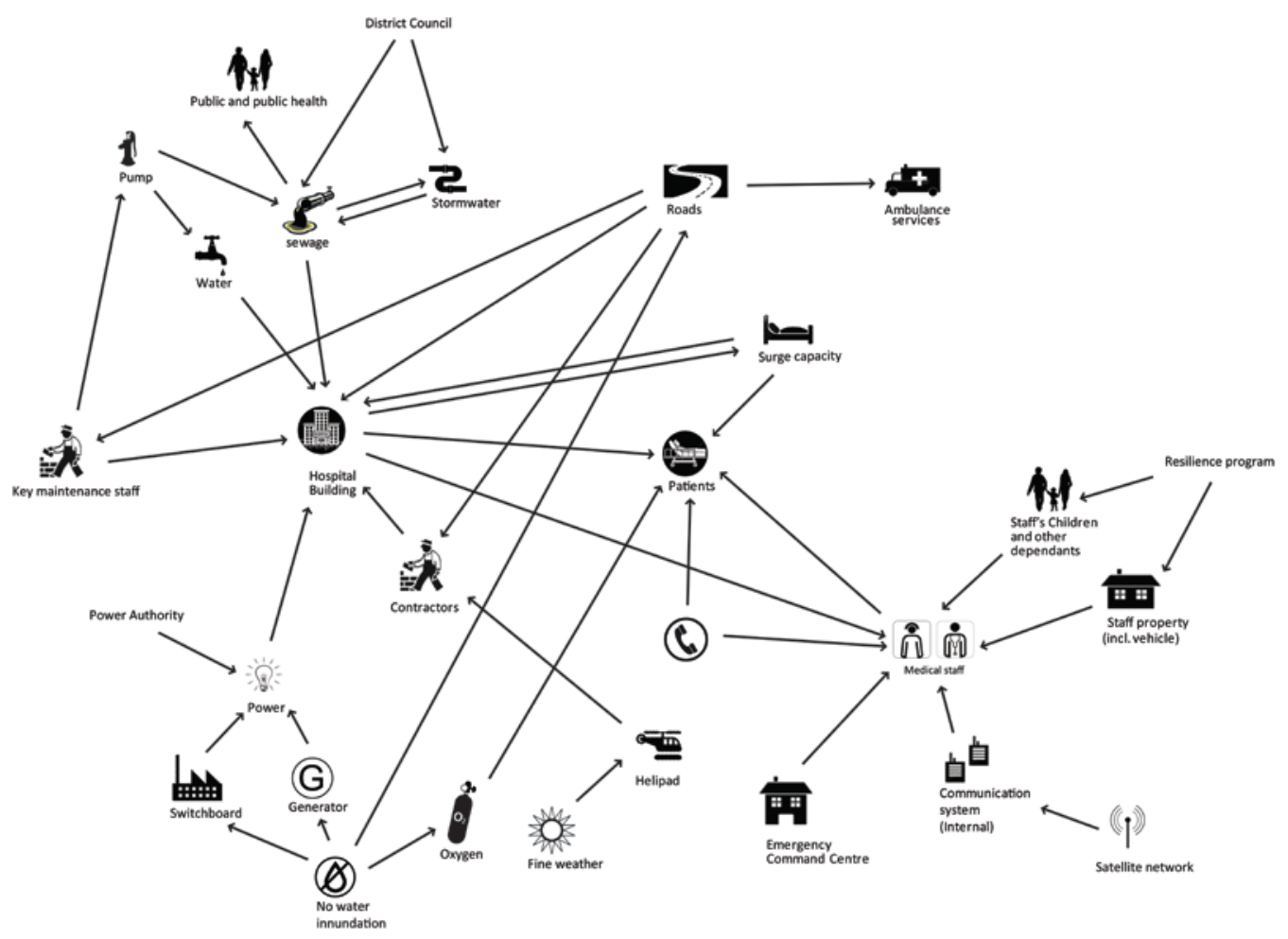

Figure 5 Rich picture diagram of Case Study 3 during and after an extreme weather event 


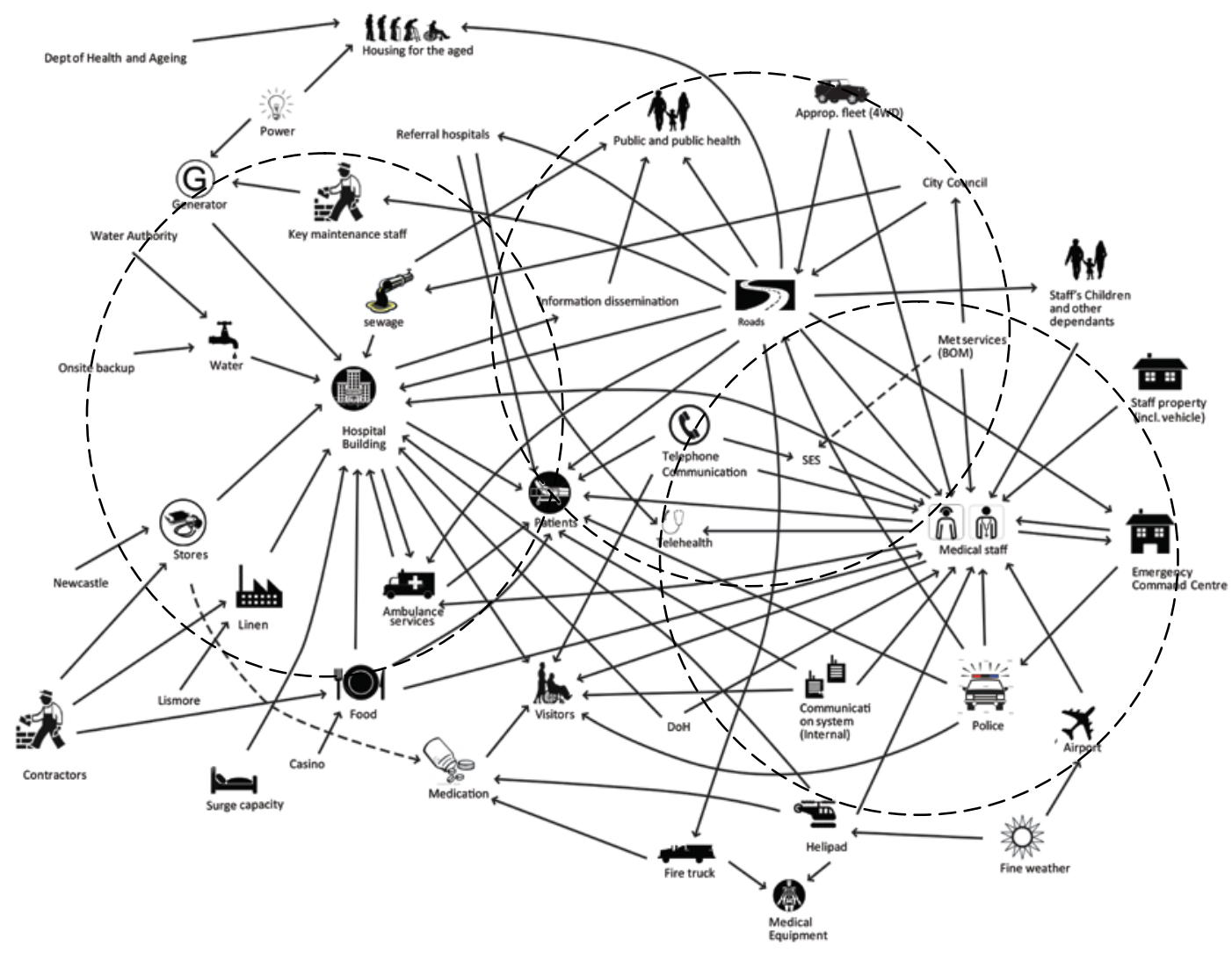

Figure 6 Clusters in Case study 1 